\title{
Comparison Study of Sound Transmission Loss in High Speed Train
}

\author{
Tae Min Kim ${ }^{\dagger}$ and Jeung Tae Kim*
}

\begin{abstract}
Many studies for improving the railway vehicle's performance and comfort such as speed, weight and noise are currently in progress. Improving the structural characteristics of the vehicle for greater noise insulation is considered important for reducing disturbance due to noise, but measuring transmission loss entails large costs. This study explores an alternative method for estimating and measuring the railway vehicle's transmission loss that involves on applying the numerical analysis coupled with scaled reverberation chamber measurement. The transmission loss measurement using scaled reverberation chamber was performed after the compensation value was found through $1 \mathrm{~mm}$ thickness(1t) specimen. For numerical analysis, a commercially available acoustics solver VA ONE was used. The proposed method is found to lead to transmission loss measurement comparable to the measurements based on large-scale reverberation chamber. Thus, it can be argued that a reliable method has been developed for measuring railway vehicle's transmission loss.
\end{abstract}

Keywords : Transmission loss, Honeycomb panel, Small reverberation chamber, Local resonance, High speed train

\section{Introduction}

Recently many railway technology studies that focus on the convenience of passengers such as riding comfort and amenity have been undertaken in addition to existing studies on making rolling stocks faster and lighter. The interior noise-limit standard of Korean high-speed rail rolling stock is $71 \mathrm{~dB}(\mathrm{~A})$ in open area and $75 \mathrm{~dB}(\mathrm{~A})$ in tunnel at the operating speed of $350 \mathrm{~km} / \mathrm{h}$. It is stricter than $70 \mathrm{~dB}(\mathrm{~A})$ in open area and $80 \mathrm{~dB}(\mathrm{~A})$ in tunnel at $300 \mathrm{~km} / \mathrm{h}$ suggested by American Public Transit Association in U.S. [1].

The internal structure of the electric multiple units (EMU) currently under development is made of aluminum, different from existing rolling stocks internal structure made of steel. The resulting rolling stock is lighter, However, becoming lighter is not good from the viewpoint of noise. The weight of train has been reduced by one third by changing the structural material from steel to aluminum; however, the noise reducing capacity has been

\footnotetext{
Corresponding author: Doctoral candidate, Hong Ik University

E-mail : wowbranden@aol.com

* Professor, Hong Ik University
}

also reduced by approximately $10 \mathrm{~dB}$ in the region where the mass law is applied. The reason is that, in the mass law region, the sound insulation performance of the rolling stock increases when the mass is bigger and the frequency is higher. Therefore, in order to compensate this sound insulation disadvantage and rolling stock strength improvement, studies and analyses from the designing stage of rolling stock are required [2].

The EMU has the power source distributed in each rail car; therefore, the interior noise level becomes higher since the sound insulation performance has decreased. In other words, since the interior noise of high-speed train decreases when the sound insulation performance of car body increases, the car body structure should have good sound insulation performance in order to reduce the interior noise of high-speed train [3].

The floor and wall of rolling stock are in laminated composite structure made of plates; therefore, it is difficult to test rolling stock as a whole. There are also issues of space and cost to consider in testing to verify the performance of the rolling stock using specimen. ISO recommends that the volume of reverberation chamber for the measurement of sound insulation performance to be designed as bigger than $50 \mathrm{~m}^{3}$. ISO also defines the size of specimen to be $8.5 \sim 12 \mathrm{~m}^{2}$. The 


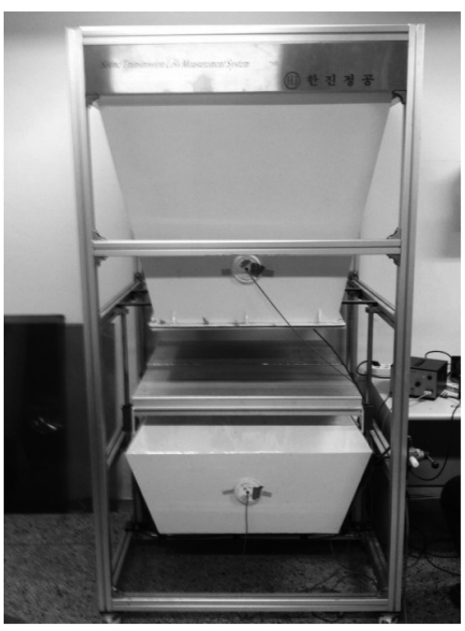

(a) Scaled reverberation chamber

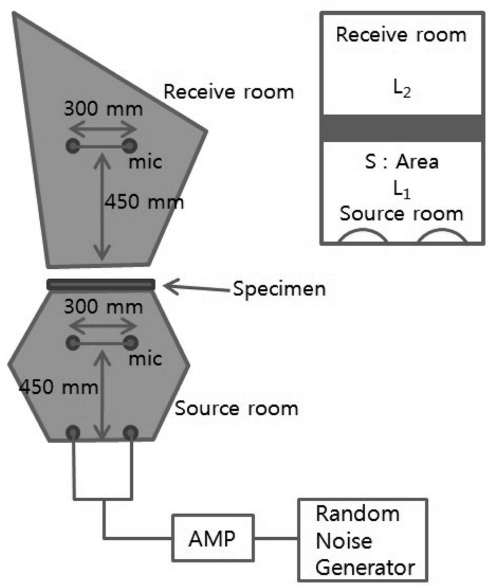

(b) Schematic of scaled reverberation chamber with experimental set up

Fig. 1 Scaled reverberation chamber

ISO recommendations are too big and inefficient for the development study of sound insulation material.

Accordingly, this study introduces an alternative methodology capable of forecasting and measuring the sound insulation performance of high-speed rail rolling stock structure in place of using large reverberation chamber suggested by ISO $[4,5]$. In addition, the results of this alternative method are compared and analyzed with the transmission loss results obtained from testing on large reverberation chamber. First, a scaled or small reverberation chamber consisting of lower sound source chamber and upper sound receiving chamber has been built based on the specimen (which is used to measures the transmission loss measurement of train structure). Then, the sound insulation performance is measured. In addition, the transmission loss is forecasted by using numerical analysis technigue that is increasingly used in many recent studies. In this study, the sound analysis commercial software VA ONE of ESI Company is used.

The transmission loss of high-speed rail rolling stock using small reverberation chamber and numerical analysis had been measured and is forecasted to be similar to the transmission loss measurement results using large reverberation chamber. Therefore, it is expected that this method can be utilized as a useful tool in sound insulation performance evaluation of high-speed rail rolling stock structures.

\section{Measurement of TL using Scaled Reverberation Chamber}

\subsection{Composition of scaled reverberation cham- ber and noise characteristic}

Table 1 Specifications of Scaled Reverberation Chamber

\begin{tabular}{ccc}
\hline & Source room & Receiver room \\
\hline Specification & Steel $4.5 \mathrm{t}$, Urethane & Steel $4.5 \mathrm{t}$, Urethane \\
\hline Area & $2.75 \mathrm{~m}^{2}$ & $4.3 \mathrm{~m}^{2}$ \\
\hline Volume & $0.37 \mathrm{~m}^{3}$ & $0.62 \mathrm{~m}^{3}$ \\
\hline
\end{tabular}

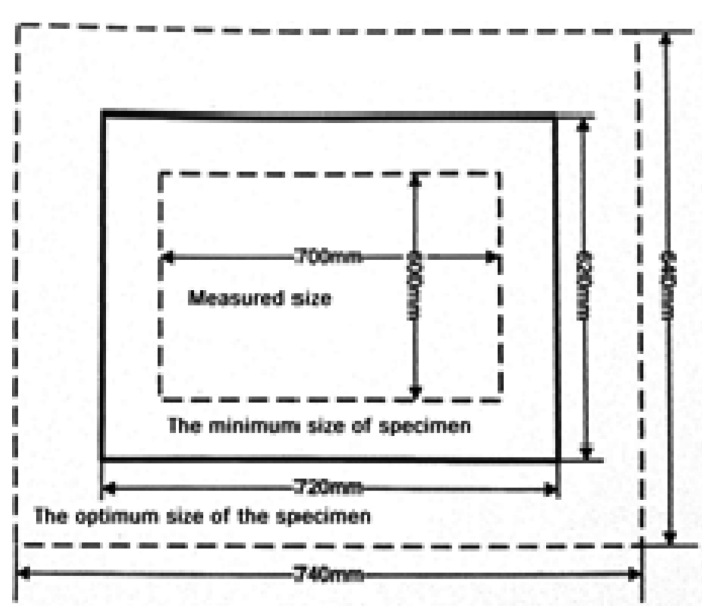

Fig. 2 Range of specimen size

The small reverberation chamber used in this study consists of structure (sound source chamber, sound receiving chamber, and supporting structure), sound source generation device, sensor rotating device, sound source chamber elevating device and system control device as shown in Fig. 1.

The noise generation device used during the transmission loss measurement of extruded material has two 
speakers facing different directions at the floor of sound source chamber. The sound source chamber and sound receiving chamber have sensor rotating device so that the noise level at different locations in each chamber can be measured. The specifications of small reverberation chamber are given in Table 1.

The minimum size of the specimen is $720 \times 620 \mathrm{~mm}^{2}$. It is possible to install up to $+10 \mathrm{~mm}$ for width and height. The optimum size for test is $740 \times 640 \mathrm{~mm}^{2}$. Fig. 2 shows the size of specimens that can be used [6].

\subsection{Transmission loss of HST}

Fig. 3 is the flow chart of the measured reverberation time using small reverberation chamber. In order to calculate the transmission loss of plates using small reverberation chamber, the sound absorption rate test of sound receiving chamber should be done first [7].

The reverberation time is measured and the sound absorption rate of sound receiving chamber is calculated. The reverberation time is the time required for the noise to be decreased down to $60 \mathrm{~dB}$ level. In this study, white

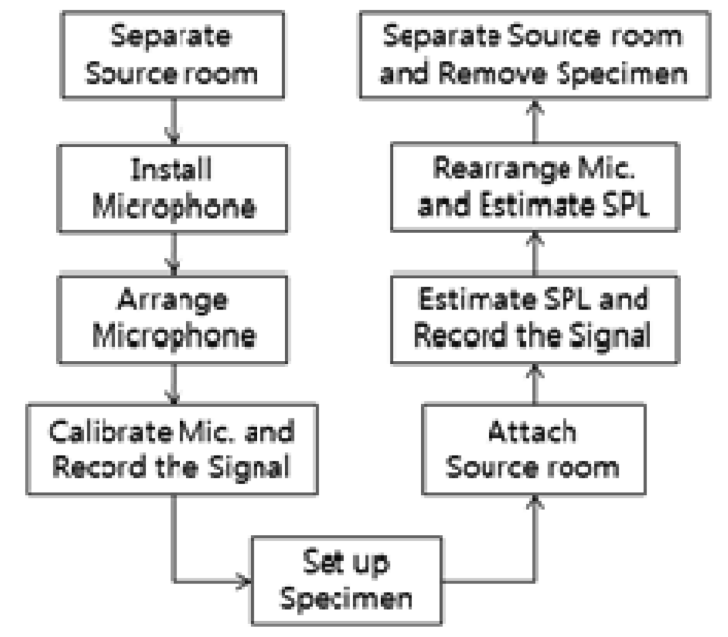

Fig. 3 Experimental flow chart

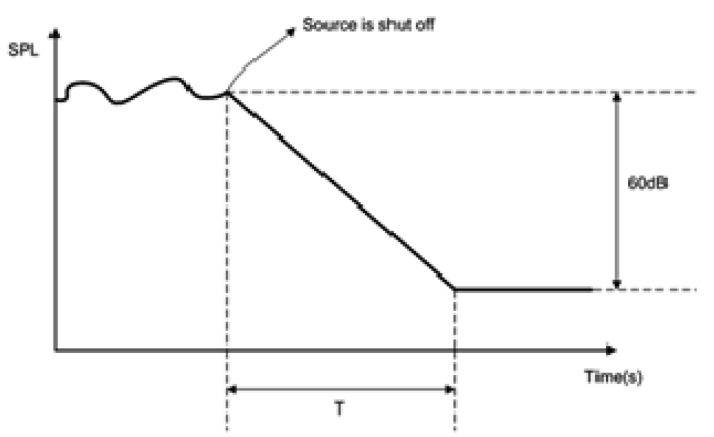

Fig. 4 Reverberation time noise had been generated in the noise room and the reverberation time of $1 / 3$ octave band at sound receiving chamber was measured using microphone (4189A, 4190) from B\&K Company and the signal analysis tool, the "PULSE".

The sound absorption rate of sound receiving chamber is calculated by using the reverberation time of $1 / 3$ octave band measured in the sound receiving chamber.

Sound absorption coefficients in a reverberation $\operatorname{room}\left(\alpha_{0}\right)$

$=\frac{0.161 \times V}{S \times T_{0}}$

$\mathrm{V}:$ Volume of receiver room

$S$ : Surface of receiver room

$\mathrm{T}_{0}$ : reverberation time

The sound absorption rate with specimen attached is calculated by the sound absorption rate before the specimen was attached and the reverberation time. The specimen is installed between the sound source chamber and sound receiving chamber to measure the reverberation time after the specimen was attached. Since sound can leak through the perimeter of specimen, the sound leakage should be prevented as far as possible.

$$
\alpha_{r}=\frac{0.161 V}{s}\left(\frac{1}{T}-\frac{1}{T_{0}}\right)+\bar{\alpha}_{0}
$$

$\mathrm{s}:$ Surface of specimen

$\mathrm{T}:$ Reverberation time after specimen set up

$\mathrm{T}_{0}$ : Reverberation time before specimen set up

$\alpha_{0}$ :Sound absorption coefficients in receiver room

The sound absorption rate of specimen is calculated by reverberation chamber method and following formula (2).Thetransmission loss measurement using small reverberation chamber is calculated by measuring the sound pressure of each frequency at sound source chamber and sound receiving chamber. It has been measured in this study by $1 / 3$ octave band from $200 \mathrm{~Hz}$ to $4000 \mathrm{~Hz}$. Then the sound pressure measured for 20 seconds was averaged for calculation. The transmission loss value was calculated by following formula using the sound absorption force in the sound receiving chamber and the sound pressure of sound source chamber [6].

Transmission Loss $=\mathrm{L}_{\mathrm{P} 1}-\mathrm{L}_{\mathrm{P} 2}+10 \log \left(\mathrm{s} / \mathrm{\alpha}_{2}\right)$

$\mathrm{L}_{\mathrm{P} 1}$ : sound pressure level in source room

$\mathrm{L}_{P 1}$ : sound pressure level in source room

$\alpha_{2}$ : Sound absorption force in receiver room

The transmission loss measurement using small reverberation chamber needs compensation because it uses scaled-down reverberation chamber, which is not real reverberation chamber. The transmission loss of object 
specimen using the compensation value is calculated by following formula.

$\mathrm{TL}_{\text {field }}=$ Experiment result $-\mathrm{C}_{\mathrm{f}}$

$\mathrm{TL}_{\text {diffuse }}=$ Experiment result $-\mathrm{C}_{\mathrm{d}}$

$\mathrm{TL}_{\text {field }}$ : Result of field incidence

$\mathrm{TL}_{\text {diffuse }}$ : Result of diffuse incidence

Therefore, two sound insulation performance values can be obtained by one test data.

\subsection{Low frequency limit}

The extreme low frequency to realize the diffused sound field within the sealed space is obtained by following formula suggested by Scharton and others [8].

$$
\mathrm{F}_{\text {low }}=\left(\frac{\mathrm{c}^{3} \mathrm{MT}_{\mathrm{R}}}{8.8 \pi \mathrm{V}}\right)^{\frac{1}{2}} \cong 485\left(\frac{\mathrm{M}}{\mathrm{S} \alpha_{\text {sab }}}\right)
$$

Here, $\mathrm{T}_{\mathrm{R}}$ is reverberation time, $\mathrm{V}$ is volume sound source chamber, $\mathrm{S}$ is internal area of sound source chamber and $\alpha_{\text {sab }}$ is Sabine sound absorption rate. In addition, $\mathrm{M}$ is the modal overlap factor which can be obtained by following formula.

$$
\mathrm{M}_{\mathrm{i}}=\omega \eta_{\mathrm{i}} \mathrm{n}_{\mathrm{i}}(\omega)
$$

In order to obtain a stabilized diffused sound field from the formula suggested by Scharton, $M$ should be more than $1 / 3$. From this formula, it was possible to confirm that the extreme low frequency decreased when the sound absorption rate was increased for sound source chamber with same area.

\subsection{Compensation Value of small reverbera- tion chamber using 1t Specimen}

The compensation value of small reverberation chamber was obtained by using $1 \mathrm{t}$ specimen. The specimen had been located between the sound source chamber and sound receiving chamber of small reverberation chamber and

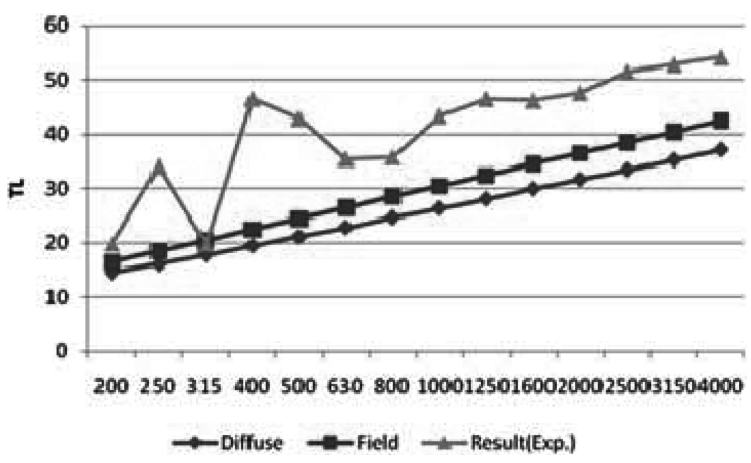

Fig. 5 Transmission loss of flat panel (1t)
Table 2 Compensation Value of Scaled Reverberation Chamber

\begin{tabular}{ccc}
\hline Frequency $(\mathrm{Hz})$ & Field $\left(\mathrm{C}_{\mathrm{f}}\right)$ & Random $\left(\mathrm{C}_{\mathrm{d}}\right)$ \\
\hline 200 & 3.23 & 5.17 \\
\hline 250 & 15.63 & 17.95 \\
\hline 315 & -0.65 & 2.02 \\
\hline 400 & 23.94 & 26.96 \\
\hline 500 & 18.41 & 21.72 \\
\hline 630 & 8.96 & 12.55 \\
\hline 800 & 7.18 & 11.06 \\
\hline 1000 & 12.87 & 16.99 \\
\hline 1250 & 14.07 & 18.42 \\
\hline 1600 & 11.57 & 16.16 \\
\hline 2000 & 11.03 & 15.83 \\
\hline 2500 & 13.02 & 18.01 \\
\hline 3150 & 12.35 & 17.54 \\
\hline 4000 & 11.57 & 16.96 \\
\hline & &
\end{tabular}

white noise was generated at sound source chamber to measure the sound pressure of each space. Fig. 5 shows the transmission loss value and theoretical value of $1 \mathrm{t}$ specimen using formula (4) and (5) above. Here, the sound insulation performance to the field incidence means the average of transmission wave ratios when the incoming field incidence would have angle between $0^{\circ}$ and $78^{\circ}$ against the plane. The sound insulation performance $(\mathrm{dB})$ on random-incidence means the average of transmission wave ratios when the incoming field incidence would have angle between $0^{\circ}$ and $90^{\circ}$ against the plane.

The compensation value is defined by the difference from the theoretical value after the test value by the specimen following the mass law had been obtained. It can be obtained by following formula $[9,10]$.

$$
\begin{aligned}
& C_{f}=\text { Experiment result }-R_{f} \\
& C_{d}=\text { Experiment result }-R_{d}
\end{aligned}
$$

Once the compensation value has been made by above two formulas on one standard specimen, same compensation value can be used for other specimen. This value is the characteristic value of small reverberation chamber and it can be used when the material would change. Table 2 is the compensation value of small reverberation chamber used in this study.

\subsection{Result of TL using scaled reverberation chamber}

The measurement results of rolling stock transmission 


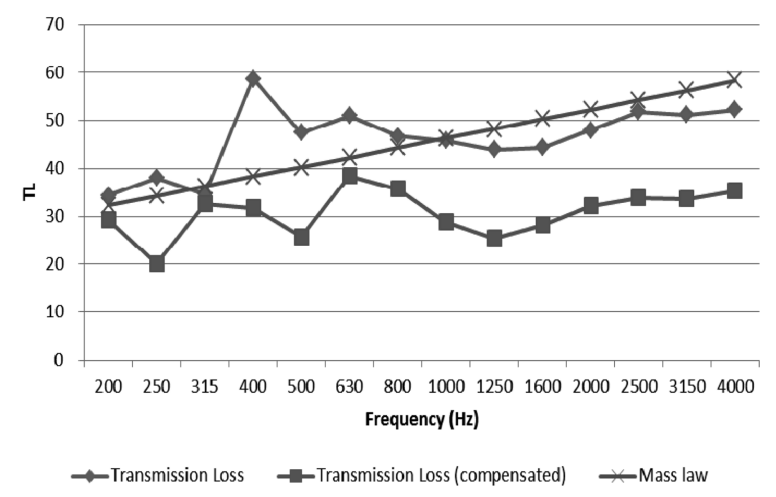

Fig. 6 Transmission loss : small reverberation chamber

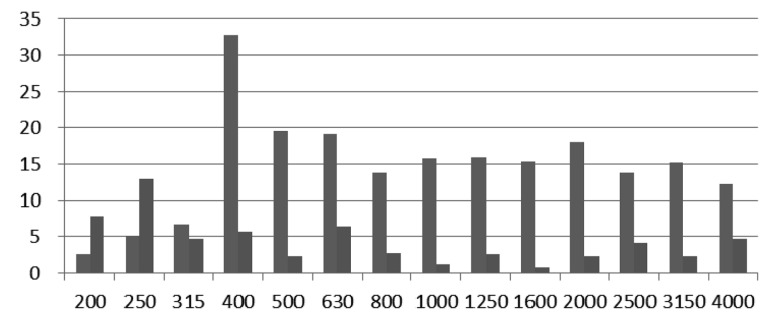

$\mathrm{Hz}$

- Difference prior to the compensation

Difference after the compensation

Fig. 7 Comparison of oftransmission loss

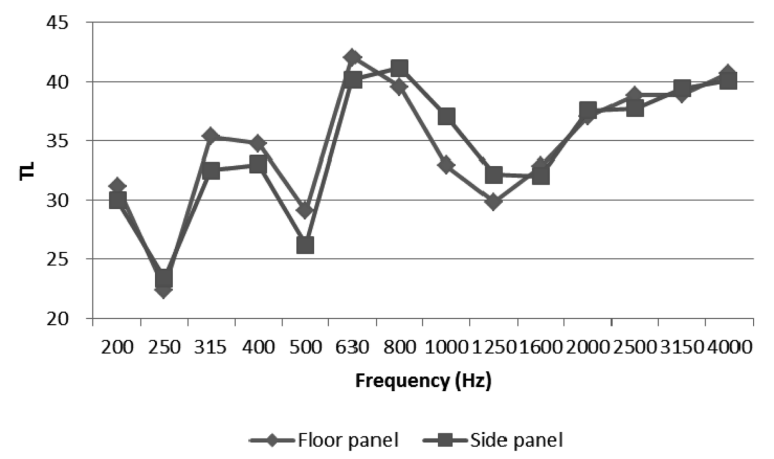

Fig. 8 Transmission loss in HST : small reverberation chamber

loss using small reverberation chamber are shown in Fig. 6. As seen in the figure, they had been measured for the floor material structure and used compensation value in Chapter 2.1.4. The floor material structure transmission loss of high-speed rail rolling stock before the compensation was measured to be bigger than the mass law in the bandwidth of $800 \mathrm{~Hz}$; however, it went down lower than mass law after the compensation.

Fig. 7 is the difference of transmission loss by large reverberation chamber test $[4,5]$ and small chamber test. As seen in the figure, the transmission loss results using small reverberation chamber before the compensation were $14 \mathrm{~dB}$ in average. However, the results of small reverberation chamber after compensation showed average $3 \mathrm{~dB}$ difference from the transmission loss result using large reverberation chamber. It means that very similar results were obtained. Therefore, it is believed that the small reverberation chamber can be used when measuring the transmission loss of high-speed rail structure material.

Fig. 8 is the measurement results of transmission loss after compensation for the floor and wall of high-speed rail rolling stock using small reverberation chamber.

\section{Estimation of TL using Numerical Analysis}

\subsection{Estimation of honeycomb panel}

The transmission loss is different dependent on the incidence condition; however, in general, the transmission loss for the random incidence is calculated. The measurement method in such case is that first, the test material is installed between the two reverberation chambers. Then the average sound pressure level in sound source chamber and the average sound pressure level of sound receiving chamber are measured. As last, the reverberation time within sound receiving chamber is measured and the calculation is made using formula (3) $[11,12]$.

In this chapter, in order to forecast the transmission loss of aluminum extruded material with fluids between the plates, the transmission loss of high-speed rail rolling stock car body structure is forecasted by using "diffusefield reciprocity" [13] like in Fig. 9. The diffused sound field relationship means that the structural resonant mode interferes with the radiant impedance in proportion within the diffused sound field by global excitation.

Figure 10 is the transmission loss analysis model established on VA ONE [14].

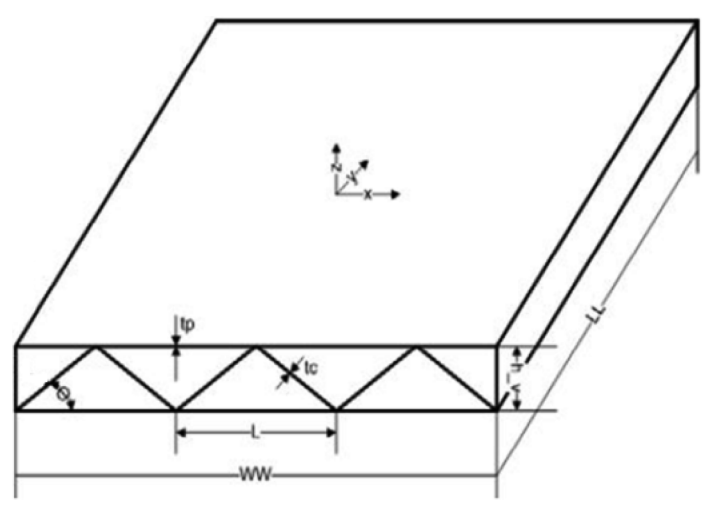

Fig. 9 Structure of honeycomb panel 


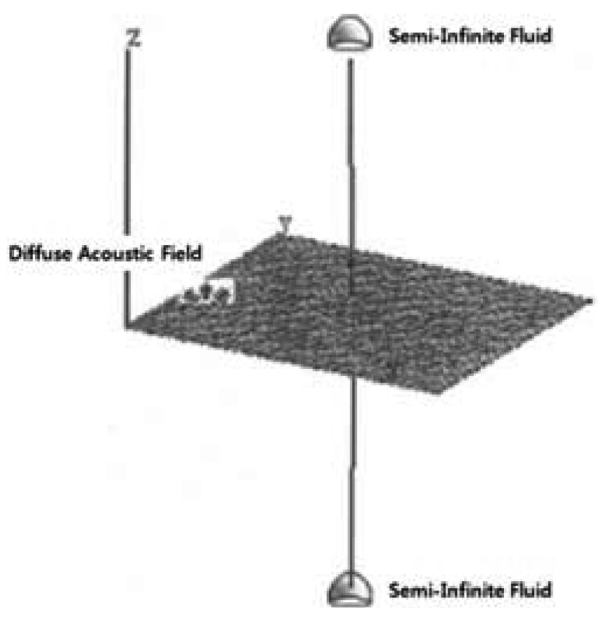

Fig. 10 Analysis of modeling in $V A O N E$

As seen in Fig. 10, regarding theeigensolution where phase constants $\left(\varepsilon_{\mathrm{x}}, \varepsilon_{\mathrm{y}}\right)$ exist, the radiation stiffness of "semi-infinite fluid" linked to 'i' plane is summarized in formula 10 below.

$$
\begin{aligned}
& D_{\text {rad }}^{(i)}\left(\varepsilon_{x}, \varepsilon_{y}, \omega\right)= \\
& \frac{1}{\pi^{2}} \iint_{-\infty}^{\infty}\left|\tilde{\Phi_{\varepsilon_{x}}, \varepsilon_{y}}\left(k_{x}, k_{y}\right)\right|^{2} G_{i}{ }^{*}\left(k_{x}, k_{y}, \omega\right) d k_{x} d k_{y}
\end{aligned}
$$

Here, $\mathrm{G}_{\mathrm{i}} \mathrm{is}$ 'green function spatial Fourier transform' on free sound field and $\varnothing$ is 'spatial Fourier transform' of displacement [15]. $\mathrm{k}_{1}$ is sound wave number of source cavity and $\mathrm{A}$ is the area of each surface.

$$
\begin{aligned}
& \tau(\omega)
\end{aligned}
$$

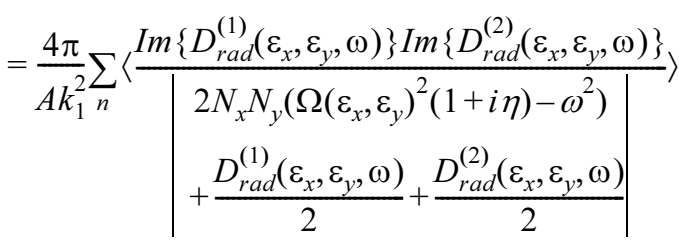

The transmission loss can be obtained by following formula (11). $\operatorname{Im}\{\}$ is the imaginary number part and $\Delta \omega$ is the frequency band. $\mathrm{N}_{\mathrm{x}}$ and $\mathrm{N}_{\mathrm{y}}$ are number of extruded material on each axis of analysis model; when same structure would be extended on the $\mathrm{x}$ axis and $\mathrm{y}$ axis of extruded material, in other words, when the repeated models would be analyzed [15].

\subsection{Result of TL using numerical analysis}

In this chapter, the transmission loss of high-speed rail rolling stock was forecasted by sound analysis commercial software VA ONE. Numerical analysis was done to forecast the transmission loss of high-speed rail rolling stock

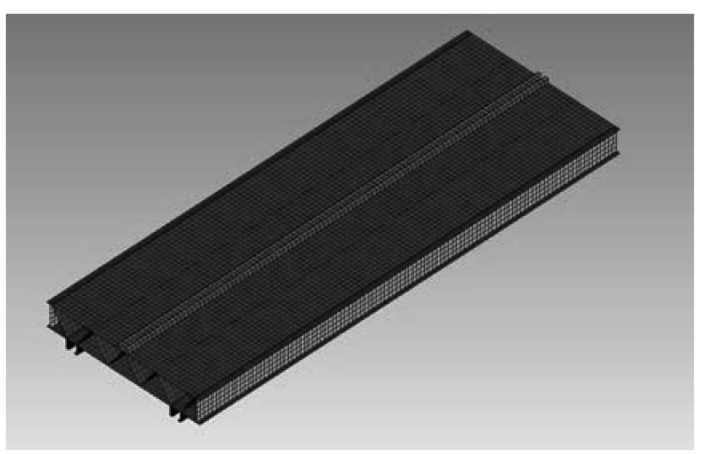

Fig. 11 Floor panel of HST

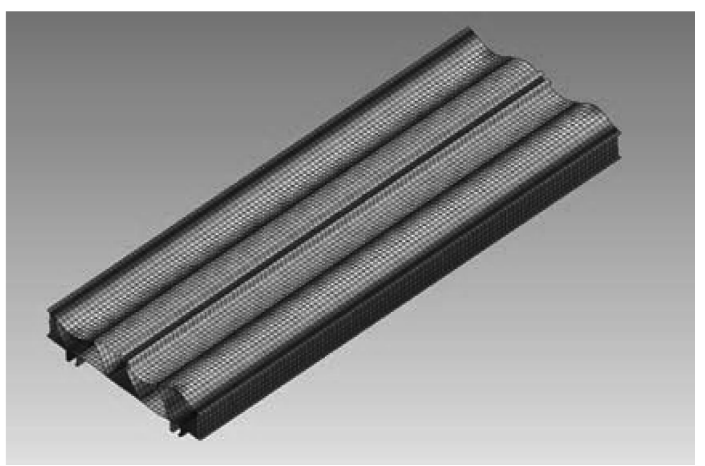

Fig. 12 Local resonance mode of floor panel

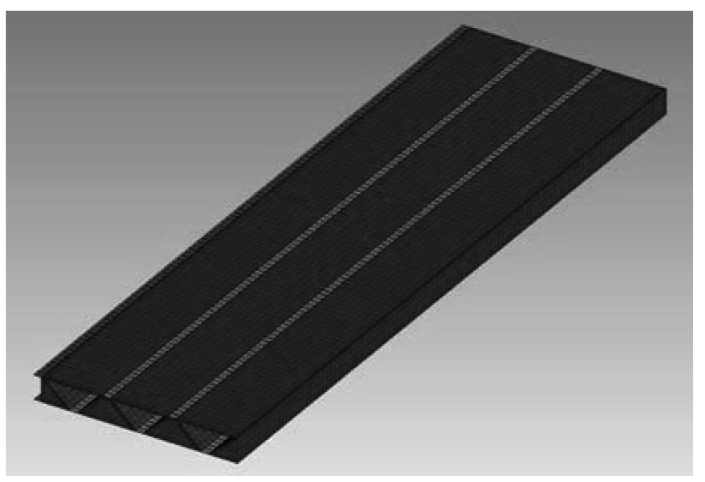

Fig. 13 Side panel of HST

car body structure using "diffuse-field reciprocity", in order to forecast the transmission loss of aluminum extruded material with fluids between the plates, like in Fig. 10.

Modeling in VA ONE was done in order to analyze the transmission loss on floor and wall, the high-speed rail rolling stock car body structure [16]. The focus was made on the local resonant mode, which does not get big impact from specimen size or boundary condition and sensitive to the wrinkle specification of wrinkled part. The length of specimen for modeling was $1.5 \mathrm{~m}$. The modeled specimen was analyzed for major bending, distortion, resonant mode 


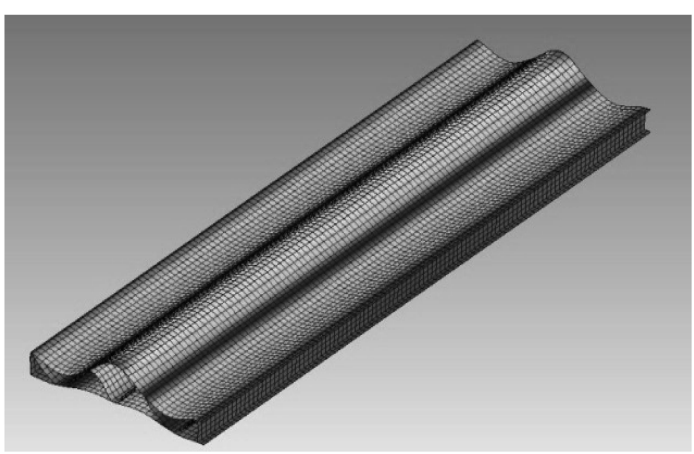

Fig. 14 Local resonance mode of side panel

Table 3 Resonance Frequency of Each Panel

\begin{tabular}{cccc}
\hline & $\begin{array}{c}\text { Global } \\
\text { bending mode }\end{array}$ & $\begin{array}{c}\text { Global } \\
\text { torsion mode }\end{array}$ & $\begin{array}{c}\text { Local } \\
\text { resonance mode }\end{array}$ \\
\hline Round ceiling panel & 182.57 & 133.99 & 567.92 \\
\hline Side panel & 162.58 & 248.02 & 449.26 \\
\hline Floor panel & 247.34 & 268.22 & 588.38 \\
\hline
\end{tabular}

phenomenon and resonant frequency using NASTRAN, a commercial program for limited elements analysis [17,18].

Fig. 11 is the floor of high-speed rail rolling stock modeled by VA ONE. As seen in the figure, transmission loss analysis was done by modeling a single specimen.

In case of floor specimen of high-speed rail rolling stock, the first local resonant mode was interpreted at $588.38 \mathrm{~Hz}$. The main bending mode was interpreted at $27.34 \mathrm{~Hz}$ and the distortion mode was interpreted at 268.22 Hz. Fig. 12 shows the first local resonant mode phenomenon on the floor of EMU.

In the high-speed rail rolling stock, the wall has very important role in reducing the noise coming from outside. Fig. 13 shows the EMU high-speed rail rolling stock wall as modeled by $V A O N E$.

The first local resonant mode of high-speed rail rolling stock was $449.26 \mathrm{~Hz}$. It was possible to confirm that it appears at relatively lower frequency bandwidth than other car body structure. The main bending mode sensitive to the size of specimen was interpreted at $162.58 \mathrm{~Hz}$ and the distortion mode was interpreted at $248.02 \mathrm{~Hz}$. Fig. 14 shows the first local resonant mode phenomenon on the wall of high-speed rail rolling stock.

Table 3 is the summary of the first bending mode, distortion mode and local resonant mode for each specimen of high-speed rail EMU. Since the specimen is smaller than real rolling stock, the major bending and distortion mode of real rolling stock will be much lower than the value suggested here; however, the local resonant mode would not be

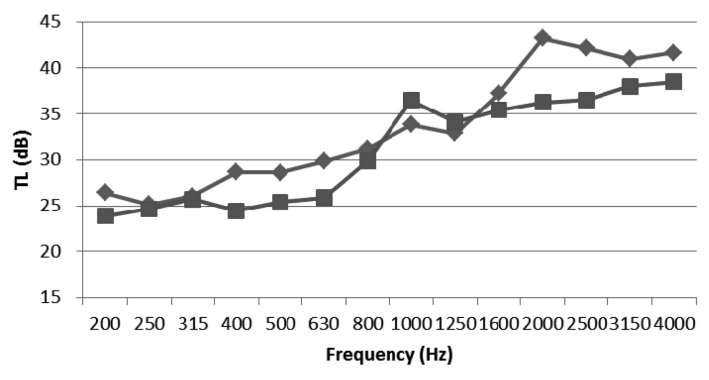

Fig. 15 Transmission loss in HST :Simulation

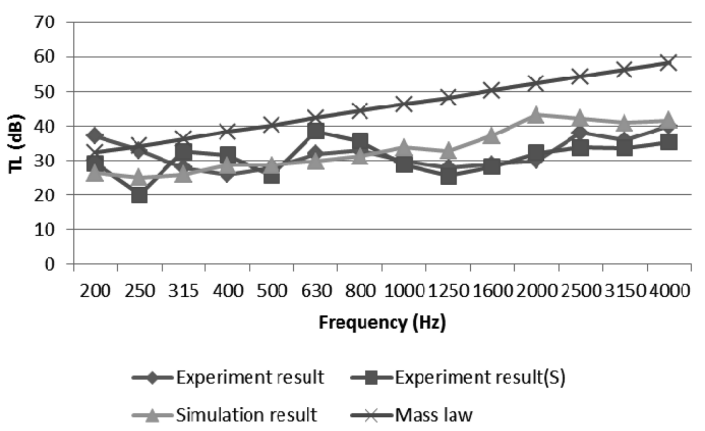

Fig. 16 Transmission loss of HST

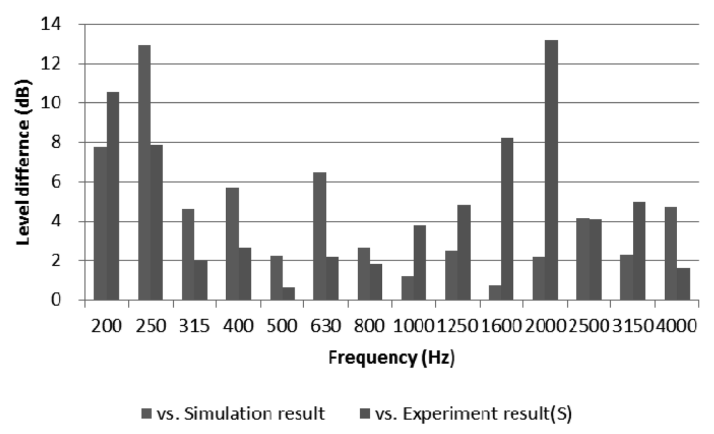

Fig. 17 Comparison of results between vs. simulation results and vs. experiment results

much different. As seen in Table 3, the local resonant mode appears after $500 \mathrm{~Hz}$; therefore, it was possible to confirm that it appears at definitely different frequency bandwidth than that of major bending mode and distortion mode.

The transmission loss of high-speed rail rolling stock was interpreted in sound analysis software VA ONE. Fig. 15 is the transmission loss of EMU as forecasted by VA ONE.

If it would be analyzed by matching the length of specimen to real rolling stock length, the major bending mode and distortion mode will have lower frequency value; however, it is believed that the frequency for the local resonant mode would be same. In addition, since, in the frequency bandwidth higher than the first local resonant mode forecasted in this study, the impact on the transmis- 
sion loss by global mode will be smaller than the impact by local resonant mode. Therefore, in the frequency bandwidth after the first local resonant mode, it is believed that the error compared to the transmission loss of real rolling stock will decrease. In other words, in the frequency bandwidth lower than the first local resonant mode forecasted in this study, the transmission loss of real rolling stock will have certain level of error; however, in the frequency bandwidth higher than the first local resonant mode, the error will be relatively smaller.

\section{Discussion}

The transmission loss of high-speed rail rolling stock car body structure was measured by test and numerical analysis. Fig. 16 shows the transmission loss of high-speed rail rolling stock floor.

As can be seen in the figure, transmission loss of highspeed rail rolling stock floor structure using small reverberation chamber was compensated by the compensation value obtained in Section 2.3. It was possible to confirm that the results are very similar to the transmission loss measured in the large reverberation chamber.

As seen in Fig. 17, the comparison of the transmission loss from numerical analysis and the transmission loss from test using large reverberation chamber yieldel maximum difference of $12 \mathrm{~dB}$ in the bandwidth of $250 \mathrm{~Hz}$; however, for greater than $315 \mathrm{~Hz}$, the results are guite similar waveforms. It is believed that the ratio of mass and strength of specimen are similar to the actual specimen; however, the damping of modeled specimen was different from the actual specimen. Therefore, if the damping can be modeled accurately during the modeling of specimen, more reliable results can be obtained. In addition, it is believed that some error has occurred because a portion of extruded material has been cut of for the small reverberation chamber test.

The measurement results using small reverberation chamber and the forecast results using numerical analysis were very similar to the actual transmission losses. In case of transmission loss measurement result of small reverberation chamber, similar results were obtained by using the compensation value.

\section{Conclusion}

The present study investigated the sound insulation performance of high-speed rail rolling stock. The large reverberation chamber recommended by ISO is inefficient with respect to the cost. Accordingly, this study introduced a methodology for studying the sound insulation perfor- mance of high-speed rail rolling stock without using large reverberation chamber and has yielded reliable results.

The extreme frequency of small reverberation chamber used in this study was $400 \mathrm{~Hz}$, which is higher than that of large reverberation chamber. Therefore, if the freguency range of interest is lower than this value, this fact has to be considened and the small reverberation chamber design should be modified. When the high-speed rail rolling stock transmission loss was measured using small reverberation chamber, the results were very similar to the results when large reverberation chamber was used. Therefore, it was possible to measure the transmission loss of high-speed rail rolling stock using small reverberation chamber, which is advantageous in terms of cost. The measurement results showed average of $3 \mathrm{~dB}$.

The transmission loss of high-speed rail rolling stock car body structure as predicted by numerical analysis showed maximum difference of $12 \mathrm{~dB}$ at $2000 \mathrm{~Hz}$ in comparison with the actual transmission loss. However, for the fregnency range of interest as a whole, the results were quite similar. It is believed that, since the forecast was on the $1.5 \mathrm{~m}$ specimen and not on the whole rolling stock, the decrease in transmission loss by the overall bending mode and distortion mode has not been properly considered. The transmission loss of the actual rolling stock's whole structure will have some error at the frequency bandwidth lower than the first local resonant mode. However, in the frequency bandwidth higher than the first local resonant mode, the impact on the global mode will be smaller. Therefore, it is believed that the result will be more reliable in this range with less error.

The transmission loss results measured and forecasted by using small reverberation chamber and numerical analysis were very similar to thosed based on large reverberation chamber. It is expected that the proposed methodology will be quite extensively used in studies on sound insulation performance of high-speed rail rolling stock in the future.

\section{Acknowledgment}

This research was supported by a grant(code $07 \mathrm{Next}$ Generation High Speed Train A01) from Railroad Technology Development Program (RTDP) funded by Ministry of Land, Transport and Maritime Affairs of Korean government.

\section{References}

1. Kim, K. J., Kim, S. S. and Park, J. K. (2008)."Research on the transmission loss analysis of the honeycomb structure's 
floor section," Journal of the Korea Society for Railway, Vol. 11, No. 1, pp. 1-6.

2. Kim, W. K., Kim, J. T., Kim, G. J. and Kim, S. H. (2003). “A study on transmission loss characteristics of honeycomb structure," Journal of the KSNVE, Vol. 13, No. 1, pp. 19-25.

3. Kim, T. M., Kim, J. T., Kim, J. S. and Kim, S. Y. (2010). Numerical analysis of transmission loss prediction in high speed trains, Journal of the KSNVE, Vol. 20, No. 8, pp. 703709.

4. Lee, Y.-H., Kil, H.-G., Kim, H.-M., Song, J.-H., Hong, S.-Y., Kim, N.-S. and Lee, C.-W. (2009). "Study on analysis of sound transmission characteristics of shipboard panels using a scale reverberation chamber," Proceedings of the KSNVE Annual Fall Conference, pp. 611-612.

5. Kim, G. J., Kim, W. K., Yoon, T. J. and Kim, J. T. (2003). "Calculation of coupling loss factor for small reverberation cabin using statistical energy analysis," Proceedings of the KSNVE Annual Spring Conference, pp. 797-801.

6. Kim, G. J., Kim, S. S. and Lee, G. H. (2007). "A study of transmission loss of floor panel on HST," Final report

7. B\&K, "Pulse User Manual".

8. Park, J. K. (1999). "Evaluation method of the transmission loss using small reverberation room," Master Thesis, Hong ik University

9. Kim, W. K., Kim, J. T. and Kim, S. H. (2002). "Evaluation of the sound transmission loss of a light weight honeycomb structure," Proceedings of the Korea Society for Railway Annual Spring Conference, pp. 1316-1320.

10. Kim, W. K. and Kim, J. T. (2001). "Evaluation method of the transmission loss for railway vehicle structures," Proceedings of the Korea Society for Railway Annual Spring Conference, pp. 155-161.

11. Kim, J. C. and Kim. K. J. (2007). "Prediction of interior noise for tilting train by using transmission loss," Journal of the Korea Society for Railway, Vol. 10, No. 4, pp. 405-408.

12. Park, J. K. and Kim, J. T. (1999). "Evaluation method of the transmission loss using small reverberation room," Proceedings of the KSNVE Annual Autumn Conference, pp. 870-875.

13. Shorter, P. J. and Langley, R. S. (2004). "On the reciprocity relationship between direct field radiation and diffuse reverberant loading," Journal of the Acoustic Society of America 117 , pp. 85-95.

14. ESI, "VA One 2009 User's Guide, Theory \& QA".

15. Williams, E. G. (1999). "Fourier acoustics : sound radiation and near field acoustical holography," Academic Press 1999.

16. Kim, S. H., Paek, I. S., Lee, H. W. and Kim, J. T. (2008). "Prediction model of the sound transmission loss of honeycomb panels for railway vehicles," Journal of the Korea Society for Railway, Vol. 11, No. 5, pp. 465-470.

17. Kim, S. H., Park, J. C. and Kim, J. N. (2000). "Sound transmission loss of aluminium extruded panels for railway vehicle," Proceedings of the KSNVE Annual Spring Conference, pp. 662-668.

18. ESI, "VA One 2009 Tutorials Guide".

Received (March 18, 2011), Revised (March 28, 2011), Accepted (March 28, 2011) 